\title{
Un recorrido por el acervo filmográfico de la Secretaría de Salud de México
}

\author{
A look through the Mexican Department \\ of Health's film archive
}

\section{María Rosa Gudiño Cejudo}

Pesquisadora do Instituto Nacional de Salud Pública/México.

San Felipe 229-207

03330 - Delegación Benito Juárez - México, DF - México

maria.gudino@insp.mx
GUDIÑO CEJUDO, María Rosa. Un recorrido por el acervo filmográfico de la Secretaría de Salud de México. História, Ciências, Saúde Manguinhos, Rio de Janeiro, v.19, n.1, jan.mar. 2012, p.325-334

\section{Resumen}

Desde finales de la década de 1920, el uso del cine como una herramienta de educación higiénica se popularizó en México y, a lo largo de los años, se convirtió en un eficiente medio de propaganda para que el Estado y las autoridades sanitarias promovieran sus proyectos, recreando en las películas la imagen de un país sano y moderno. En este texto muestro los resultados del trabajo de rescate y catalogación del acervo filmográfico de la Secretaría de Salud los cuales me han permitido reconstruir la cartelera cinematográfica nacional e internacional - principalmente estadounidense - que se vio y se produjo en México entre 1943 y 1960.

Palabras clave: cine; educación higiénica; campañas de salud; intermediarios sanitarios; México.

\section{Abstract}

Since the late 1920s, cinema has been a popular tool in health education in Mexico; over the years, it functioned as an efficient means of propaganda through which the State and public health authorities promoted their projects and re-created the image of a healthy, modern country on screen. The article presents the results of an effort to recover and catalogue the Mexican Department of Health's film archive, an endeavor that allowed for the reconstruction of a list of national and international films screened and produced in Mexico from 1943 to 1960, especially from the United States.

Keywords: cinema; hygienic education; health campaigns; social workers; Mexico. 
$\mathrm{E}$ 1 cine fue una herramienta de educación higiénica de gran importancia en las campañas de salud nacionales en el siglo XX. A la par que buscó educar al espectador, lo entretuvo e involucró en tramas en donde la salud versus enfermedad se representó de diferentes formas. Desde la heroica entrega de los médicos a su oficio de curar hasta las tragedias individuales o familiares provocadas por la negligencia o ignorancia de quienes, al no tomar medidas preventivas contra la enfermedad, oscilaban entre la vida y la muerte. En aras de promover cómo conservar la salud, las películas siempre mostraron los métodos para evitar el paludismo, la tuberculosis y la sífilis, entre otras enfermedades, y fomentaron los beneficios de la vacunación y las prácticas de hábitos higiénicos.

El Departamento de Salubridad Pública, desde 1917 y a partir de 1943, la Secretaría de Salubridad y Asistencia (SSA) utilizaron el cine como un instrumento de educación higiénica para las campañas que organizaron. Así lo demuestran los informes de médicos, brigadistas y maestros rurales que solicitaron películas para proyectarlas en sus jornadas educativas. Por su parte, el Boletín del Departamento de Salubridad publicaba los títulos de las películas utilizadas en las campañas de salud. Con esta información fue posible constatar que en el marco de la Campaña Nacional Contra las Enfermedades Venéreas, iniciada en 1927 en la ciudad de Toluca (México), se exhibieron las películas estadounidenses Al final del camino (The end of the road; 1919) ${ }^{1}$ y Listos para vencer (Fit to win; 1919) ${ }^{2}$ que todavía a mediados de los años 1930 eran solicitadas por médicos para proyectarlas en comunidades campesinas.

Las mismas fuentes reportan actividades de la campaña estadounidense Salud Para las Américas (Health for the Americas), promovida por Nelson Rockefeller desde la Oficina del Coordinador de Asuntos Interamericanos (Office of Inter American Affairs, OIAA) que se implementó en América Latina durante la década de 1940 para educar 'higiénicamente' a la población rural. En México, este proyecto inició en 1943 y en materia de educación higiénica el cine fue su principal herramienta de difusión. Lo novedoso en este proyecto de educación higiénica fue la participación del cineasta Walt Disney quien produjo 13 cortometrajes con dibujos animados. ${ }^{3}$ Más allá de una simple animación para niños, esta serie formó parte de la amplia filmografía estadounidense en temas de salud e higiene que fue exhibida en México en el marco de las campañas sanitarias y sus programas de educación higiénica llevadas a cabo durante la primera mitad del siglo XX. Como hemos visto, nuestro único referente sobre el tipo y procedencia de películas que se veían en México en materia de salud pública hacia finales de la década de 1940, apunta al cine estadounidense. Aún no había sido posible corroborar la existencia de películas mexicanas y, mucho menos, reconstruir el stock cinematográfico de la Secretaría de Salubridad y Asistencia.

\section{Tras la pista de un acervo}

El interés por localizar físicamente las películas anunciadas en los Boletines citados y encontrar alguna evidencia que confirmara la existencia de películas mexicanas guió mis pasos hacia el Archivo Histórico de la Secretaría de Salud. ${ }^{4}$ Afortunadamente, la búsqueda no fue infructuosa y, para mi sorpresa, cientos de películas enlatadas de $16 \mathrm{~mm}$ y $35 \mathrm{~mm}$ estaban allí guardadas en espera de su traslado a la Filmoteca de la Universidad Nacional Autónoma de México (Unam) para ser dictaminadas y catalogadas. ${ }^{5}$ En noviembre del 
2006 abrimos las latas y, como si hubiésemos abierto la caja de Pandora, el trabajo de catalogación de más de 150 películas documentales con dibujos animados y actores de carne y hueso se convirtió en una tarea sistemática y llena de sorpresas. ${ }^{6}$

Ahora conocemos cuántas películas mexicanas y extranjeras conformaron el stock de la Secretaría de Salubridad y Asistencia, qué temas predominan, cuáles fueron los mensajes con los que productores y autoridades sanitarias intentaron sensibilizar a los mexicanos del siglo XX en relación con el valor de la salud y la higiene. ${ }^{7}$ También identificamos a directores, fotógrafos y productores que filmaron en México y participaron en la realización de películas sobre salud y combate a enfermedades. Los mexicanos Francisco del Villar ${ }^{8}$, Adolfo Garnica ${ }^{9}$, Felipe Morales, Demetrio Bilbatúa, Juan Hernández Arvizu y los extranjeros Walter Reuter, Jack Chertok y Herbert Knapp son algunos de ellos. Así mismo, la participación de la Lotería Nacional para la Asistencia Pública, la sección 49 del Sindicato de Trabajadores de la Industria Cinematográfica (STIC 49), Rivatón de América para musicalizar los documentales y las voces en off de Agustín Barrios Gómez o Manuel Méndez, entre otros, estuvieron detrás de la elaboración de estos cortometrajes.

Para sistematizar la información, utilizamos una ficha de catalogación con los campos necesarios para registrar el título del documental, el tema predominante y los sub-temas que se desprenden de éste. Cuando fue posible identificar el lugar en el que se filmó el documental, se anotó en su apartado correspondiente. Lo mismo sucedió con los personajes y la fecha, en el campo 'personajes' se anotó el nombre de los protagonistas y no su nombre de pila; este último se anotó cuando apareció en los créditos o los actores fueron identificados. En general, las películas presentan un aceptable estado de conservación.

Con respecto a su contenido temático, tenemos los siguientes temas identificados con el número de cortometrajes para cada uno: Adicciones (AD), 4; Alimentación y nutrición (A-N), 11; Anatomía (AN), 3; Anticoncepción (ANT), 4; Campañas de salud (CS), 58; Científico (C), 6; Educación sexual (ES), 3; Formación de personal (FP), 5; Infancia (INF), 6; Planificación familiar (PF), 7; Recursos naturales (RN), 4; Salud Mental (SM), 3; Serie televisiva Decisión, 7; Serie Datos Para el Pueblo, 4; Otros (O), 17.

Los cinco cortometrajes más antiguos son de los años 1940 (1941-1949) y a partir de estas fechas tenemos materiales de las décadas subsecuentes hasta la de 1980. La oferta temática que ofrece este corpus es amplia, pero la mayor parte de las películas tiene como eje articulador la representación de las campañas de salud, su modus operandi y sus protagonistas. A partir de este tema central, presentaré a continuación algunos ejemplos.

De factura estadounidense Disentería y La viruela (ca.1946-1948) fueron realizadas por el citado Jack Chertok y el fotógrafo Herbert D. Knapp, enviados por la Oficina de Asuntos Interamericanos para completar la cartelera cinematográfica, encabezada por Walt Disney en 1943. Ambos cineastas, con previo permiso de la Secretaría de Salubridad y Asistencia, visitaron México en 1946 para filmar varios documentales sobre las condiciones sanitarias e higiénicas de los mexicanos. Les antecedía su trabajo en Bolivia, Perú y Costa Rica en donde también filmaron documentales relacionados con este tema. Una de las condiciones para que realizaran su trabajo fue que no incluyeran 'escenas denigrantes' y, en cambio, sí mostraran los trabajos que realizaban las autoridades sanitarias en aras de mejorar las condiciones higiénico-sanitarias de los mexicanos y su entorno. ${ }^{10}$ 
De esta dupla de cineastas estadounidenses existen en este acervo tres películas y su contenido está orientado a contar una breve historia del enfermo. En La viruela, Juan es ciego porque su madre no tuvo el cuidado de vacunarlo a tiempo. Para prevenir a su esposa e hija del contagio de la enfermedad, se explican con detalle los pasos que deben seguir al asistir al centro de salud y sobre todo, nunca rechazar la visita de una enfermera visitadora. La intención es promover la prevención, pero, también, señalar la irresponsabilidad de la gente. Los cortometrajes son hablados en español y actuados por actores mexicanos. ${ }^{11}$

Las representaciones de quienes formaron las brigadas sanitarias de una campaña mereció la atención de cineastas y documentalistas. Los personajes más representados son las enfermeras, los sanitaristas, el maestro rural, las trabajadoras sociales y los rociadores de DDT activos en la Campaña Nacional de Erradicación del Paludismo de 1957. Su formación profesional así como el desarrollo de su trabajo en campo fueron temas recurrentes.

Por ejemplo, Hombres marcados (Fernando Hernández Arvizu, 1961) se desarrolla en una comunidad del estado de Guerrero que sufre por un brote de mal de pinto. Al llegar allí, el oficial sanitario intenta sensibilizar a la población para que reciba con gusto los

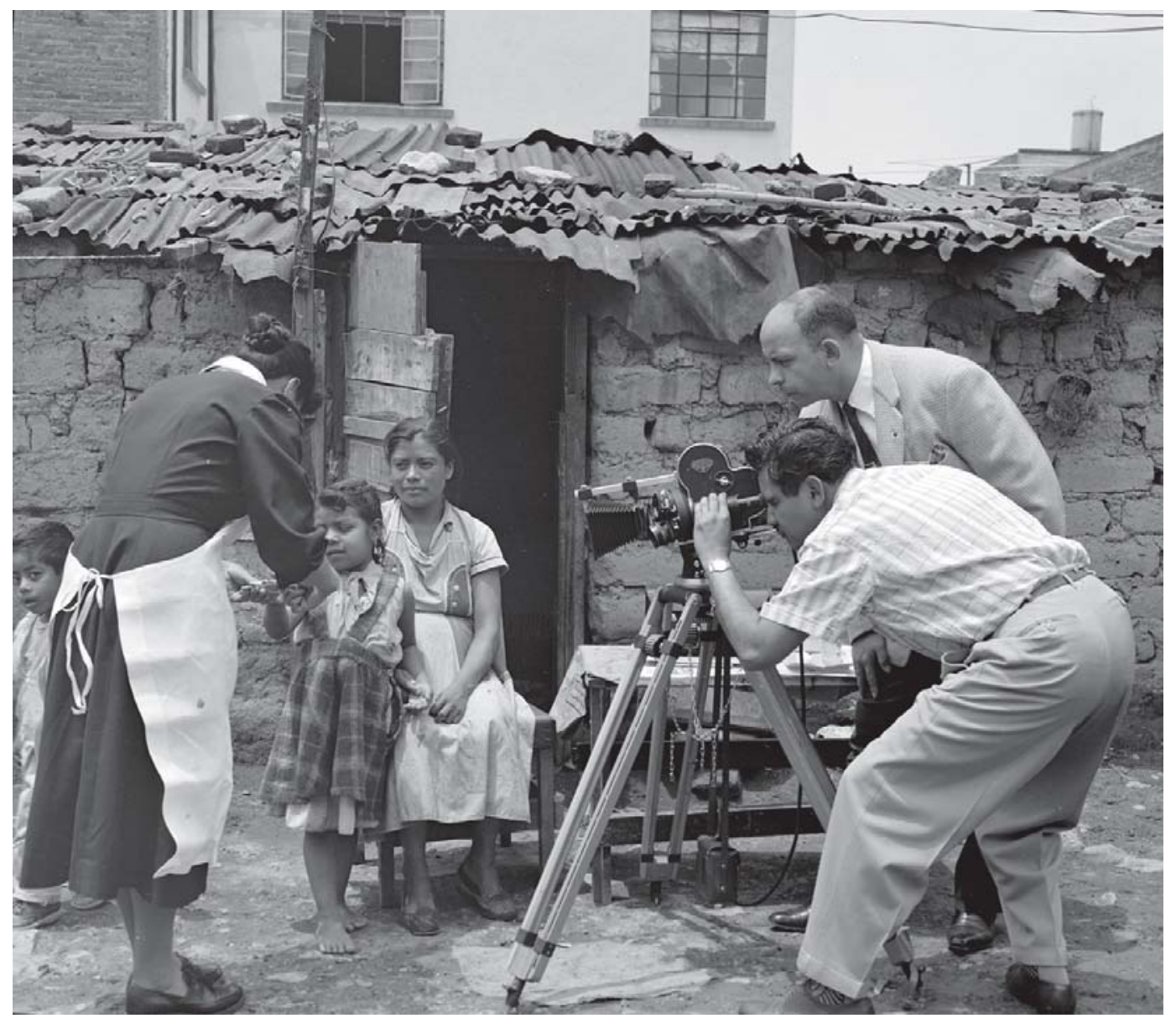

Figura 1: Filmación de una trabajadora social vacunando a una niña. (Dirección de Promoción de la Salud, Secretaría de Salud, México) 


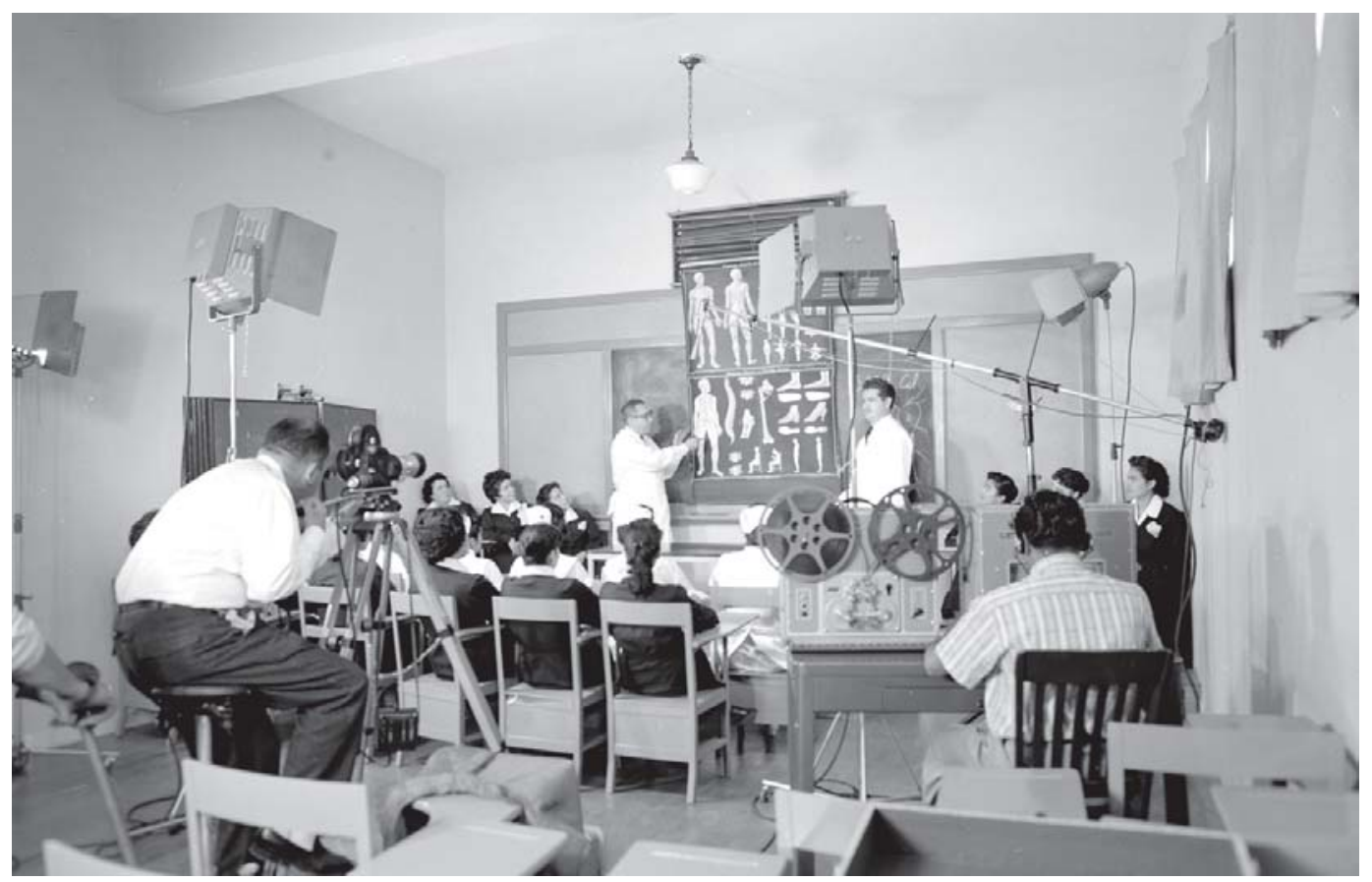

Figura 2: Filmación de una clase de medicina impartida a enfermeras. (Dirección de Promoción de la Salud, Secretaría de Salud, México)

beneficios que traerá consigo la brigada médico-sanitaria. Ésta llegaría al día siguiente con el tratamiento de penicilina para tratar a los enfermos o 'manchados' como se les llama en el cortometraje. El rechazo de la población a este personaje es evidente y eso dificulta su trabajo, pero, al final, gracias a la intermediación de un niño de la comunidad, los adultos aceptan el tratamiento médico que los brigadistas les ofrecen.

Lo mismo sucedió a la trabajadora social que en Pasos en la arena (Francisco del Villar, 1960) visita a una madre agobiada por el quehacer doméstico, la pobreza y, como si fuera poco, por el aviso de que su hijo será dado de baja de la escuela.

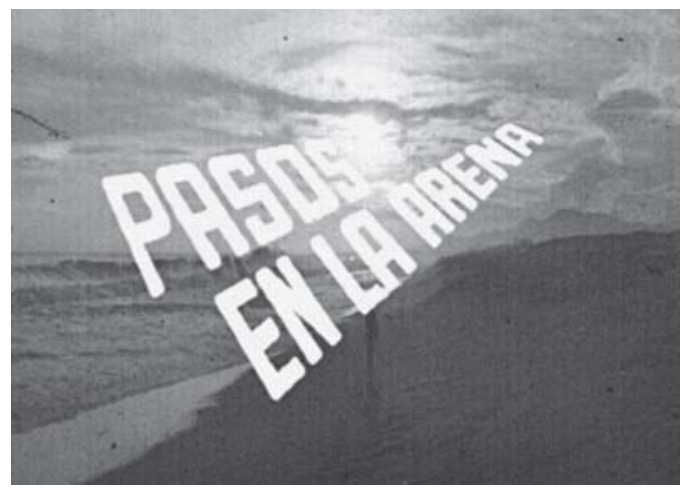

Figura 3: Fotograma de Pasos en la arena. Colección Archivo Histórico Secretaría de Salud (Filmoteca Unam)

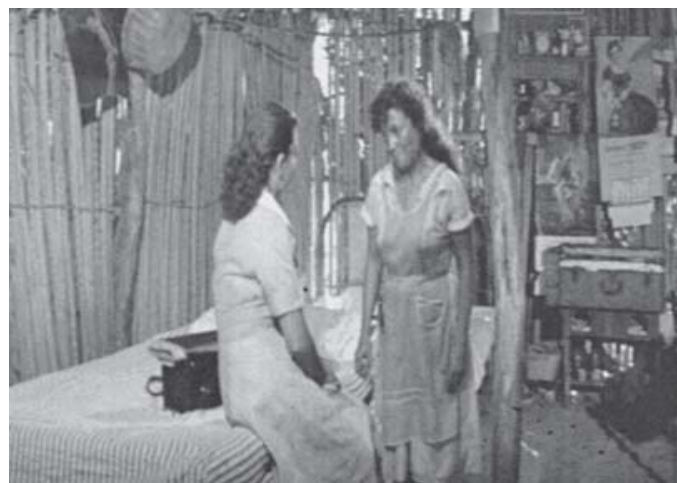

Figura 4: Fotograma de Pasos en la arena. Colección Archivo Histórico Secretaría de Salud (Filmoteca Unam) 
En Cruzada heroica (Francisco del Villar, 1960), el director además de exaltar el trabajo de la Campaña Nacional de Erradicación del Paludismo y a sus organizadores, lo hace con quienes fueron el enlace con la población: los rociadores, definidos como los pilares de la campaña o soldados de la salud, porque fueron ellos quienes trabajaron intensamente en las aéreas rurales y urbanas para fumigar las casas y evitar la reproducción del moquito anopheles, agente transmisor de esta enfermedad.

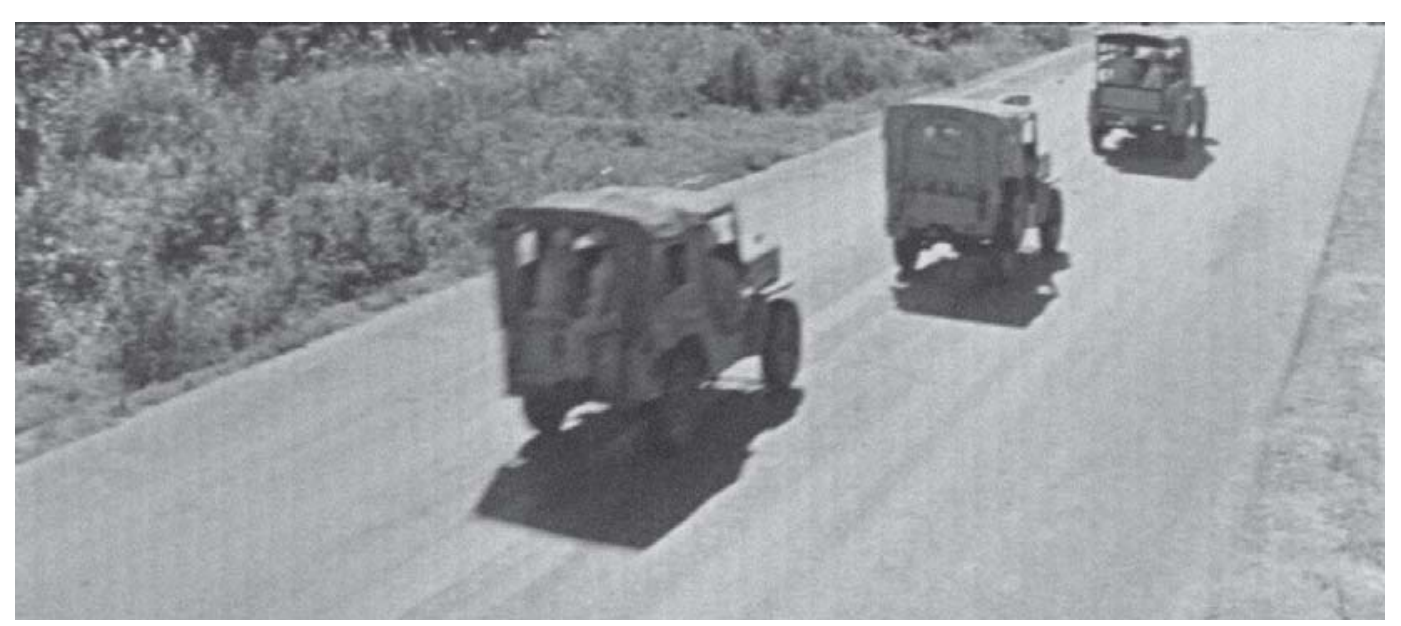

Figura 5: Fotograma de Cruzada Heroica. Colección Archivo Histórico Secretaría de Salud (Filmoteca Unam)

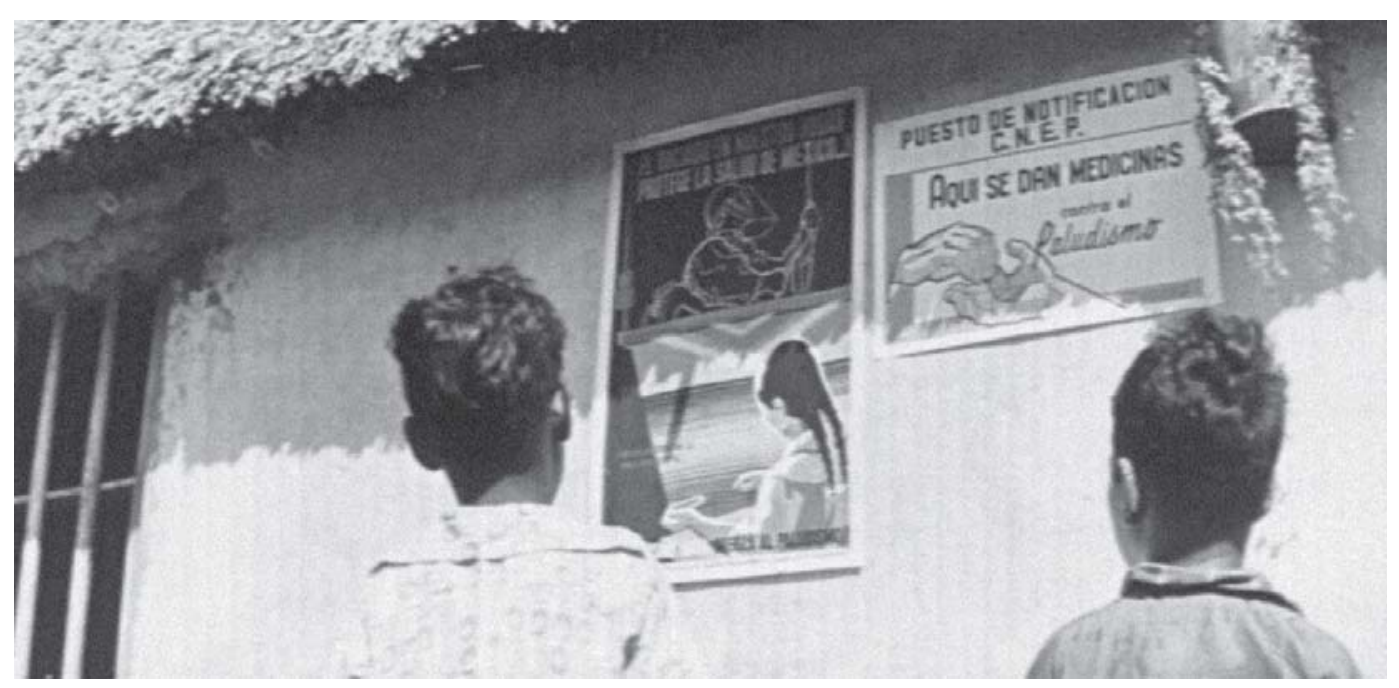

Figura 6: Fotograma de Cruzada Heroica. Colección Archivo Histórico Secretaría de Salud (Filmoteca Unam)

Otro tema tratado en cortometrajes de este acervo fue el de la migración del campo a la ciudad. Por ejemplo, en Pulmones de piedra (Dirección de Educación Higiénica, SSA, 1957), los protagonistas se trasladan a la ciudad de México en busca de trabajo y mejores condiciones vida. La vida alejada de su entorno rural no es fácil, la ciudad no los acoge como imaginaron y a cambio les ofrece desesperanza. La nueva y poco alentadora situación 
en la ciudad lleva casi siempre al protagonista, que es el padre de familia, a refugiarse en la cantina para lamentarse de su mala suerte por no conseguir trabajo o, en caso de conseguirlo, por las insalubres e inseguras condiciones en que trabaja. La visión idílica del campo, como un lugar seguro, higiénico y prometedor, les devuelve la confianza y las ganas de regresar a su casa.

En el campo de la alimentación, predominan los consejos sobre nutrición y prevención de enfermedades gastrointestinales, ocasionadas por la falta de higiene de los alimentos o de quienes los preparaban. Existe una copia de la versión mexicana del caso de Mary Thyphoid, una cocinera inmigrante que en el Nueva York de inicios del siglo XX desencadenó una epidemia de tifoidea. ${ }^{12}$ En el cortometraje La tifoidea de Jack Chertok y Herbert Knapp se recrea la historia de María, una cocinera que no sabe que es portadora de la enfermedad. Como era de esperarse, contagia a las personas para quienes trabaja, desencadenando así una epidemia de tifoidea que es controlada a tiempo por los médicos de la Secretaría de Salud. También existe en esta colección, una copia de El cuidado del niño (Infant care) que pertenece a la serie que Walt Disney filmara en 1943. El tema de este cortometraje de dibujos animados es la historia de una madre embarazada y los consejos nutricionales que recibe durante su embarazo.

Los consejos sobre educación sexual aparecen en documentales que ofrecen detalladas explicaciones sobre el funcionamiento del cuerpo humano. La educación sexual también aparece en documentales elaborados para dar cobertura a campañas nacionales contra enfermedades venéreas, como sucede en Reconquista (Dirección de Educación Higiénica/ Lotería Nacional, 1957). En este cortometraje vemos la historia de Juan, un joven ejemplar, estudioso, trabajador y recién casado. El día de su graduación, sus compañeros lo invitan al Tropicana y después, ya borrachos, se van a un cabaret en donde sigue bebiendo y pasa un rato con una joven prostituta. En medio de un discurso moralista y dramático, el contagio de sífilis se representa aquí en un ambiente de irresponsabilidad, alentado por el consumo de alcohol y la compañía de prostitutas. Juan era un joven ejemplar hasta que se vio involucrado con estos dos 'incómodos y riesgosos' acompañantes y las consecuencias no podían ser otras. Sin embargo, su larga trayectoria como individuo responsable y trabajador podía permitirle un desliz sin condenarlo a un dramático desenlace.

La salud mental es otro tema presente en tres documentales de esta colección. El cortometraje más atractivo es el titulado Puertas cerradas (Francisco del Villar, ca.1957), filmado en las instalaciones del Manicomio General La Castañeda, fundado en la ciudad de México en 1910 y destruido en 1968. En este documental podemos ver cómo se desarrollaba la vida cotidiana de los internos en el manicomio y cómo fue su traslado al Hospital Psiquiátrico Fray Bernardino, inaugurado en 1968 para recibir a los pacientes del antiguo manicomio.

Este acervo también cuenta con cortometrajes estrictamente médicos y científicos. Entonces, tenemos los que dieron cobertura a congresos médicos y cirugías. Otros promovieron el cuidado de los recursos naturales como el agua. La presencia de actores y actrices mexicanos, como recurso para promover la vacunación, se hace presente con breves spots en los que aparecen Silvia Pinal o Jacqueline Andere y futbolistas como Enrique Borja hablando de la importancia de la vacuna contra la poliomelitis. 
Mención aparte merecen las seis copias de la serie televisiva llamada Decisión: lucha por la salud (ca.1960) que se transmitía por el canal 4, los sábados a las siete de la noche. Eran programas de aproximadamente veinte minutos de duración y un reparto conformado por los actores Rebeca Iturbe y Manolo García y otros invitados como sucedió con Janet Arceo y Judy Ponte. Generalmente se representaron historias de familia cuyo drama central era la enfermedad de algunos de sus integrantes o los problemas de convivencia familiar desencadenados por algún problema de salud o adicciones.

Para cerrar este breve recorrido por el acervo filmográfico, dejé el tema de la educación higiénica al final. Las representaciones de las campañas de salud siempre trataron este tema que fue fundamental para su buena operatividad. A través de la pantalla, podemos ver representadas, en movimiento y a todo color, las funciones de teatro guiñol itinerante que recorría colonias y pueblos, a los dibujantes diseñando los carteles de propaganda para difundir consejos de prevención; así como al público infantil y adulto que asistía a las funciones de cine que se proyectaban al aire libre o en clínicas y escuelas. Como vemos en los siguientes dos fotogramas (Figuras 7 y 8), un grupo de niños se divierte viendo una película en donde el símbolo de la cruz, representativa del combate a la tuberculosis, nos habla de que fue exhibida en el marco de alguna campaña en contra de esta enfermedad.

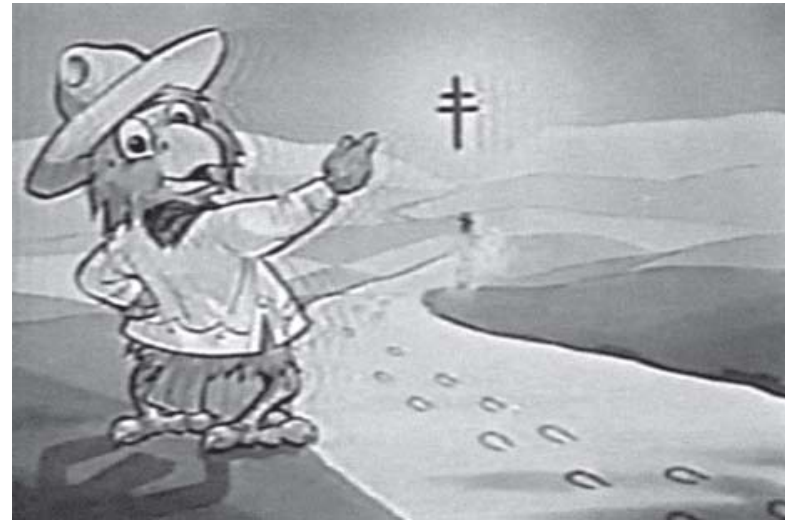

Figura 7: Fotograma de Río Arriba. Colección Archivo Histórico Secretaría de Salud (Filmoteca Unam)

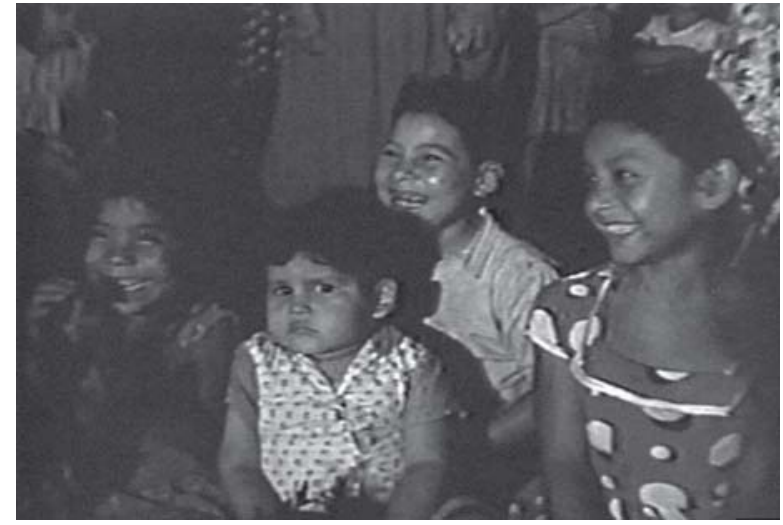

Figura 8: Fotograma de Río Arriba. Colección Archivo Histórico Secretaría de Salud (Filmoteca Unam)

Los documentales que conforman este acervo filmográfico son una muestra gráfica de cómo se representaron acontecimientos de la historia de la salud pública en México en la segunda mitad del siglo XX. La mayoría de ellos, incluyen en su trama parte de ese discurso modernizador y nacionalista que encontró eco en las campañas de salud y en la difusión de una cultura sanitaria para la población de su época. Sin duda, este material fue un valioso instrumento de educación higiénica que a la luz de los años se ha convertido en un atractivo documento histórico que nos permite, entre otras cosas, recrear e imaginar acontecimientos, espacios, paisajes y escenarios del pasado. Así mismo, ofrece posibilidades alternativas para seguir enriqueciendo el estudio de la salud pública. 


\section{NOTAS}

${ }^{1}$ Dirigida en 1919 por Edward H. Griffith, escrita por Katherine Bement Davis. Reparto: Richard Bennett como el doctor Bell, Claire Adams como Mary Lee y Joyce Fair como Vera Lynch. Es un largometraje de $35 \mathrm{~mm}$ y se encuentra en seis carretes que suman 5,900' de película (1798.32m). Existen copias en los National Archive of Record Administration, en la Motion Pictures Section de la Biblioteca del Congreso (Washington) y, según el historiador Martín Pernick, en el Museo de Arte Moderno de la ciudad de Nueva York.

${ }^{2}$ De este largometraje no fue posible localizar copia. Para conocer a detalle la trama, se recomiendan los trabajos de Adolph Nichtenhauser (ca.1950), Allan Brandt (1985) y Stacie Collwel (1992). La ficha técnica completa es: director y escritor, Edward Griffith; reparto, sgt. Raymond McKee, interpretado por Billy Hale, soldado Harry Grip, interpretado por Chick Carlton y Paul Nelly, por Hank Simpson.

${ }^{3}$ Copias de la serie completa de Walt Disney/OIAA existen en el archivo de la Fundación Rockefeller en Tarrytown, Nueva York. Sobre Walt Disney, véase, Cartwright, 1994. Para conocer una versión más detallada de la campaña Salud Para las Américas y la proyección de las películas de Walt Disney en México, véase, Gudiño Cejudo, 2009a y 2009b, p.179-203. Sobre la visita de Walt Disney a México, véase Aurrecoechea, 2003.

${ }^{4}$ El Archivo se localiza en la calle de Donceles, 55 en el Centro Histórico de la ciudad de México. Es depositario de miles de documentos escritos que permiten reconstruir la historia de la salud pública en México.

${ }^{5}$ Las películas provenían de la Dirección de Promoción de la Salud de la Secretaría de Salud que, a inicios de 2006, las remitió al Archivo Histórico en donde la licenciada Irma Betanzos tuvo la iniciativa de solicitar su traslado a la Filmoteca de la Unam. A Irma quiero agradecerle el darme las primeras pistas sobre este acervo.

${ }^{6}$ Este trabajo de catalogación hubiera sido imposible sin el incondicional apoyo de Ángel Martínez y Mario Tovar de la Filmoteca de la Unam a quienes quiero manifestar, una vez más, mi agradecimiento. Recientemente, la colaboración de Mario de Dios de la Dirección de Promoción de la Salud ha sido de gran utilidad para enriquecer la información sobre la historia y contenidos de las películas. En esta Dirección se conservan algunas copias de las películas enviadas en 2006 al Archivo Histórico de la Secretaría de Salud.

${ }^{7}$ Existen 36 películas extranjeras como evidencia de que la Secretaría de Salubridad y Asistencia mantuvo intercambio cultural y educativo con instituciones de salud de otros países. Las copias que se conservan en este acervo son de procedencia británica, francesa, argentina, brasileña, colombiana, salvadoreña y por supuesto, estadounidenses.

${ }^{8}$ Francisco del Villar nació en la ciudad de México en 1920 y murió en septiembre de 1978, a los 58 años de edad, a consecuencia de un infarto. Entonces, se desempeñaba como director de la productora estatal Conacine (Estudios Churubusco). En los inicios de su carrera dirigió cortometrajes para la Secretaría de Salubridad y Asistencia y Ferrocarriles Nacionales.

${ }^{9}$ Adolfo Garnica nació el 11 de febrero de 1930 y es conocido por su larga trayectoria como director de cortometrajes. Fue premiado nacional e internacionalmente y su cortometraje Río arriba ganó el premio Perla del Cantábrico al mejor documental de habla hispana en el Festival de Cine de San Sebastián, España, en su edición de 1961.

${ }^{10} \mathrm{El}$ permiso solicitado a las autoridades sanitarias mexicanas para que Herbert D. Knapp trabajara en México se encuentra en el AHSS, Fondo SSA, SubSya, caja 9, exp.1, 1946-1949, 57 fs. Cooperación Interamericana de Salubridad Pública, Dirección de Proyectos MEX-HE.

${ }^{11}$ Gracias a la información otorgada por Maria Teresa Bandeira de Mello, sabemos que en la Fundação Oswaldo Cruz se resguardan copias de películas de Jack Chertok y Herbet Knapp que no existen en México. Agradezco a Teresa que compartió conmigo esta información.

${ }^{12}$ Este documental se titula Tifoidea y está inspirado en el caso de la cocinera irlandesa Mary Mallon, conocida como Mary Typhoid, quien avecindada en la ciudad de Nueva York, en 1906, y trabajando en la casa de un acaudalado banquero neoyorquino fue la portadora, a través de sus guisados, de la tifoidea. En esa primera casa, contagió a seis integrantes de la familia y en su andar por diferentes casas siguió contagiando la enfermedad. Su aprehensión se dio en 1907 y en su momento su caso fue uno de emergencia sanitaria. Los directores retoman esta historia y hacen su cortometraje en versión a lo mexicano. La protagonista es la cocinera María que desencadena una ola de contagio de tifoidea. Sobre el caso de Mary Thyphoid, véase, Judith W. Leavitt, 2000. 


\section{REFERENCIAS}

AURRECOECHEA, Juan Manuel.

Paquete de sorpresas: Disney, México y Los Tres Caballeros. Revista de la Universidad Nacional Autónoma de México, México, n.620, p.129-133. 2003.

BRANDT, Allan M.

No magic bullet: a social history of venereal disease in the United States since 1880. New York: Oxford University Press. 1985.

CARTWRIGHT, Lisa.

Cultural contagion: on Disney's health education films for Latin America. In: Smoodin, Eric (Ed.). Animating culture: Hollywood cartoons from the Sound Era. New Brunswick: Rutgers University Press. p.169-180. 1994.

COLWELL, Stacie.

The end of the road: gender, the dissemination of knowledge, and the american campaign against venereal disease during WWI. Camera Obscura, v.10, n.29, p.91-129. 1992.

GUDIÑO CEJUDO, María Rosa.

Campañas de salud y educación higiénica en
México, 1925-1960: del papel a la pantalla grande. Tesis (Doctorado) - El Colegio de México, México. 2009a.

GUDIÑO CEJUDO, María Rosa.

Salud Para las Américas y Walt Disney: cine y campañas de salud en México, 1943-1946. In: Azuela, Alicia; Palacios, Guillermo (Coord.). La mirada mirada: transculturalidad e imaginarios del México revolucionario, 1910-1945. México: El Colegio de México. p.179-203. 2009b.

LEAVITT, Judith Walzer.

Thyphoid Mary strikes back: bacteriological theory and practice in early 20th century public health. In: Walzer, Judit; Numbers, Ronald L. (Ed.). Sickness and health in America: readings of medicine and public health. Wisconsin: The University of Wisconsin Press. p.555-571. 2000.

NICHTENHAUSER, Adolf.

A history of motion pictures in medicine.

Manusc. MS C 380 (U.S. National Library of Medicine). ca.1950. 